\title{
DESIGNING A SKILL TREE MODEL FOR LEARNING MEDIA
}

\author{
Fanani A. Ghozali ${ }^{1}$, Rustam Asnawi ${ }^{2}$, M Khairudin ${ }^{3}$, Mentari P Jati ${ }^{4}$, Ahmad Hoirul ${ }^{5}$ \\ 1234 Department of Electrical Engineering, Universitas Negeri Yogyakarta, Indonesia \\ ${ }^{5}$ Al Jamiah Al Malik Abdul Aziz, Saudi Arabia \\ E-mail: fanani.ghozali@gmail.com
}

\begin{abstract}
In a modern era, digital media has been created and used for educational purposes. In the educational programs, teachers have many objectives which can be converted into some important points that can be mapped on a skill tree. A skill tree is actually commonly known for building gaming media as a decision making system but it has not been widely applied for educational purposes. This paper discusses how to design a skill tree model for effective learning media. The learning objective can be mapped in the skill tree and used for decision-making to decide whether the subject matter being taught by a teacher can proceed or not. The method used in this study was the development method. The findings indicated that the skill tree can be applied as learning media. The results of product testing reveal insignificant defects and smooth operation. Therefore the developed software can be considered as an eligible product to be applied. This software is aimed to assist teachers in understanding the weaknesses of the students and improving the quality of education.
\end{abstract}

Keywords: decision making, learning media, learning process, skill tree

\section{INTRODUCTION}

In this era, teachers are required to be professional. The development of an advanced era resulted in a change in the mindset of students to be more advanced too. Professional teachers are required to master the learning media especially the latest media. The professionalism of teachers can be seen from the level of students' satisfaction and understanding. Because professionalism is an activity by a professional when serving clients and businessmen as if serving the community as a whole through the service it does [1]. Professionalization depends on creation and maintenance on at least three things: knowledge, practitioners, and customers [2].

Professionalism can be seen to have a personal and habitual behavior of dedicated, committed and highly skilled practice [3], and professionalism is an achievement of professional status as a tactic to gain strength or advantage in the marketplace [4].
In the context of a customer education as described above are students. It can, therefore, be inferred that the professionalism of a teacher is very dependent upon the satisfaction of the student. If the student is not satisfied and does not understand then the professionalism of a teacher can be doubted thus affecting the trust of the parents to teachers.

Indonesia also sets the professionalism of a teacher in the constitution. The constitution number 14 of 2005 chapter 7 of the Republic of Indonesia [5] explains the teaching profession and teachers are special line of work and have a few principles which must be implemented, namely: (1) teachers should possess talent, interest, boredom, and idealism in teaching the learners; (2) teachers should have the commitment to improve the quality of education, the students' characters and morals; (3) teachers must meet the academic qualifications and educational background in accordance with their field of expertise; (4) 
teachers must be competent in accordance with the field of assigned tasks; (5) teachers should be responsible for their professional duties; (6) teachers have the right salary determined in accordance with the work achievement; (7) teachers deserves continual professional development with lifelong learning; (8) teachers have legal protection in carrying out their professional duties, and (9) teachers must have professional organizations with power and authority to manage and organize teachers' professional duties. Based on points 2 and 5 in the constitution above, it can be underlined that the teachers should be able to improve the quality of education and teachers should be responsible for the execution of the duties of professionalism. Therefore the teacher should be able to create and master the learning media thus the quality of education is improved.

Arsyad [6] states that the media is all forms of intermediaries used by humans to communicate or spread ideas or opinion so that the ideas or opinions expressed it to the intended recipients. Therefore, learning media is the medium used to convey the subject matter in the form of ideas or opinions of the expert to the learners. Learning media in the present era are often in the form of e-learning. E-learning instructional media is stored and used on a digital device (either on computers, laptops, tablets or smartphones) that aims to help the learning process [7].

In this modern era, multimedia innovations with artificial intelligence have been created. Artificial intelligence is one of computer science formed with the goal of providing intelligence on a machine (the computer) in order to be able to work like a human [8]. Artificial intelligence is diverse in shapes, one of them is a Skill Tree System. Skill Tree is often called the technology Three or talent Three. A tree perk is a model of a system structure of graphs used to draw up development possibilities that make players proficient and master in-game characters [9]. Skill Tree is also often used for the system of decision makers and is often also referred to as a decision tree. Decision tree, as one of the best-known approach for classification method, is widely used due to simplicity to understand and their good learning capabilities [10]. A decision tree is a tool to determine the option that uses a tree-like graph or model of the determination of the decision and the possibility that may occur, including the results of the incident by chance, cost resources, and utilities [11]. A decision tree is also described as a system to provide classification based on input and information technology [12]. In other research, a skill Three is also called a value three. A value tree is used in several decision-making methods and provides a hierarchal framework to add some values to stakeholders when evaluating different options [13]. At this stage, The skill tree can be applied for education. The use of the skill tree for decision making are implemented at each learning objective. The learning objective can be mapped in the skill tree and used for decision-making to decide whether the subject matter being taught by a teacher can proceed or not.

It is possible to apply the skill tree learning media for the students. Using learning media in the learning process shows better learning outcomes [14]. Information Technology used as learning media facilitates the students to learn efficiently [15], [16]. The developed media can support the students' understanding of the subject matter which has been compiled in the syllabus and must be mastered by students. The application of the skill tree is expected 
to examine certain weaknesses of the students in the subject. This study describes a method of designing skill tree used as a medium of learning.

Some previous research that succeeded in using the skill tree was conducted by McCandless [17] who found that when using a skill tree model technique for solar generation can reduce variable prediction error between $10 \%$ and $55 \%$ compared by climatological average values of the temporal and spatial GHI standard deviation. Another research conducted by Zhao [18] found that prediction performance for listing statuses of Chinese-listed companies can be improved using a method that implement a decision tree. Based on previous research, it can be concluded that the skill tree can be used to improve the ability to predict and to analyze shortcoming in industries. However, this study focuses on designing a skill tree model for learning media that can be used for the educational world not for industrial needs.

\section{METHOD}

The method used in this study was an approach that combines two models using the waterfall model by Pressman [19] and the Dick \& Carey model [20]. The development procedure is described in Figure 1.

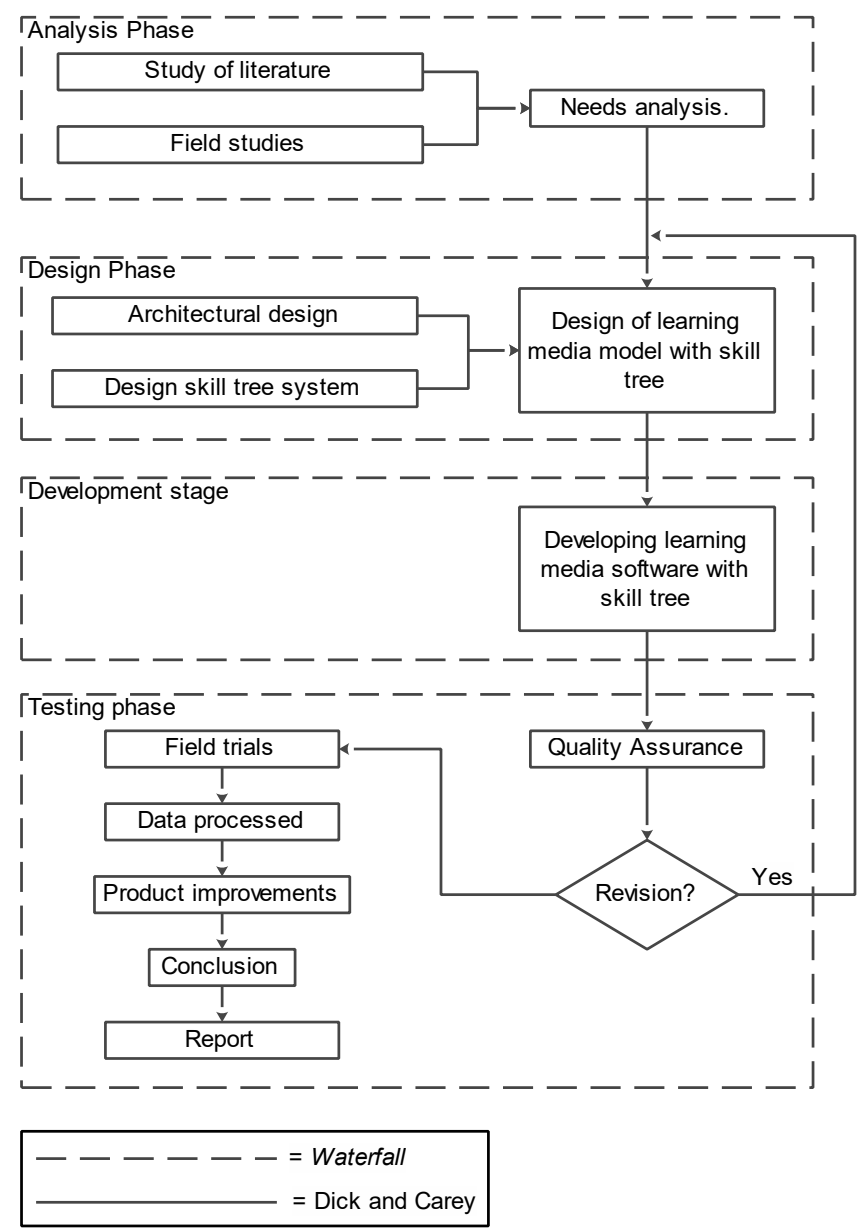

Figure 1. Skill Tree Model 


\section{RESULTS AND DISCUSSION}

The development was first started with the analysis by observation, interviews, documents, and studies. The results of observation and interviews revealed that the implementation of the skill tree as learning media does not exist or is rarely found. However, the results of a study of documents about education found only several studies about education that applied the skill tree. Heinimäki describes the use of technology trees in games and digital classification criteria on the current era to facilitate learning. Heinimäki found that the Technology trees are generally important to be applied.

There are still limited studies about technology trees. Technology trees are long once known and worked on games [9]. Therefore the use of the technology trees may work well in other fields and other purposes such as education. Another study related to the skill tree was performed by Yücel [21] who suggested how the attitude of the chemistry teachers on the application of the classification technology and wanted to create the classification as a tool guide or a tool for the performance assessment. This study supports Morcillo who found that a decision tree is a data mining technique which can be used to solve classification problems [22]. This study leads to the result that it can be used as a performance evaluation tool to do a classification of disadvantages on teachers and students and can also be used as a guide to correct their flaws [21].

Topîrceanua \& Grosseck [23] indicated that higher technology used in learning media increase difficulties to learn the material for example in e-learning. The problem is the absence of direct interaction between teachers and students thus the teachers do not know the disadvantages or problems faced by the students. Therefore, it was developed as a tool to understand the students using a decision tree/a skill tree to press the numbers of students dropping out from schools. The results of this study showed that they successfully developed useful tools for identifying both profiles, strengths, and weaknesses of the students who are doing the lessons online or using elearning.

The use of the skill tree can be used to identify deficiencies and can be used in any application other than in games.

Further analysis is the analysis of needs identification. Identification of needs which are used, among others, identification of the interface, the identification of data needs software, and the functionality. The results of the identification of the interface is obtained namely (1) page beginning; (2) log in screen; (3) main menu, (4) display the assignment, (5) user info, (6) skill tree screen, (7) option menu; (8) setting of the screen, (9) about a screen; (10) customer service screen, and (10) social network screen. For the needs of data obtained as a result like the following, (1) data storage information; (2) data storage assignment; (3) data storage skill tree; (4) data storage social network. As for the need of functionality, it brings results, (1) installation progress, (2) software update, (3) display and interactivity.

After the analysis is completed then it was performed the stage of designing and developing. The design and development stage is divided into three parts namely, (1) interface development; (2) algorithm development the skill tree; (3) development of a database of quests and the skill tree. Development of the interface is the process of creating the look of the software that serves to connect users with the software. 
Software development was based on the principle of user-friendly.

Algorithm development of the skill tree can be based on the function of the software being developed. Each function on a skill tree requires confirmation from the mentor before users can access. In general, the functionality in the skill tree can be made based on the functional model adapted from Heinimäki [9] which can be seen in Figure 2. The flowchart algorithms skill tree can be created for media development in the form of software which can be seen in Figure 3.

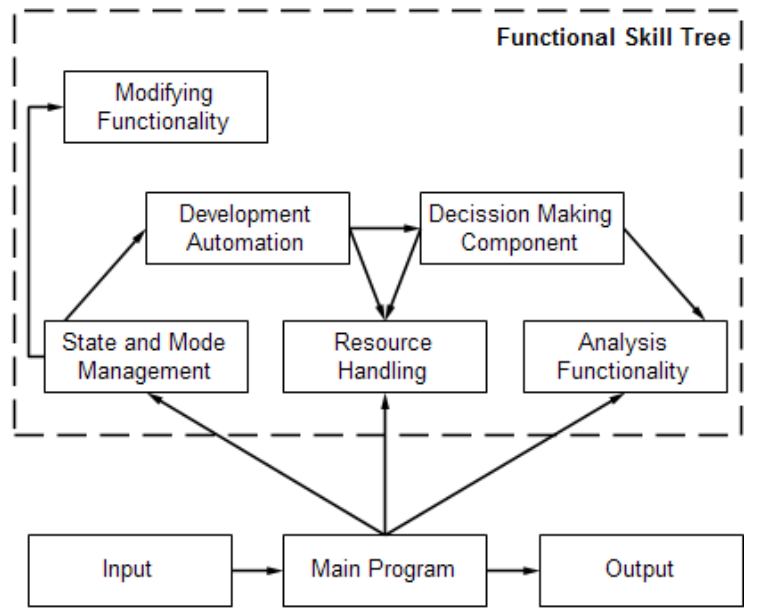

Figure 2. Functional Skill Tree Model Adapted from Heinimäki

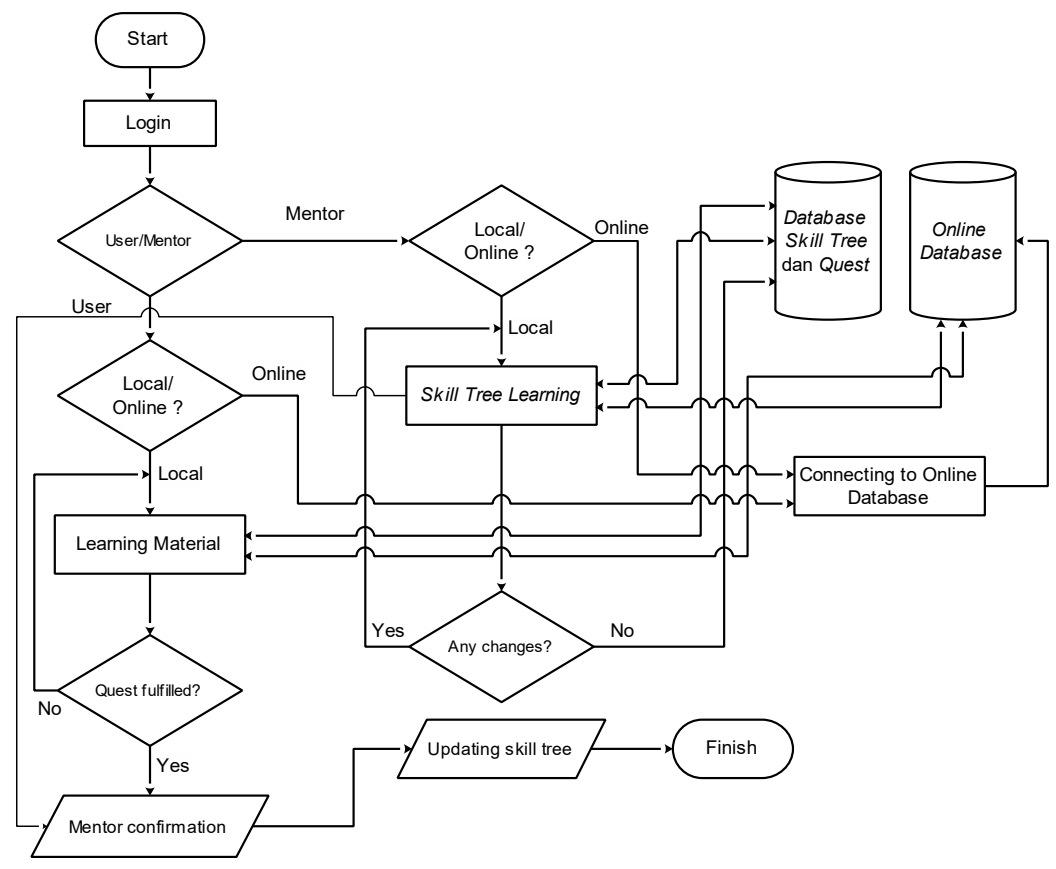

Figure 3. Flowchart Skill Tree Algorithm

Development of a database was designed to store and modify the different possibilities on the branching skill tree. The database being developed are also designed to be used to store the user's credential data online and also offline (local network). Database development of the skill tree online used the open source database that is google firebase. The development of the features of the chat feature for social network and delivery of files using the SDK open source IE Qiscus. While the overall development also uses open source software namely Android Studio. Examples of the results of the development of the interface can be seen in Figure 4. 


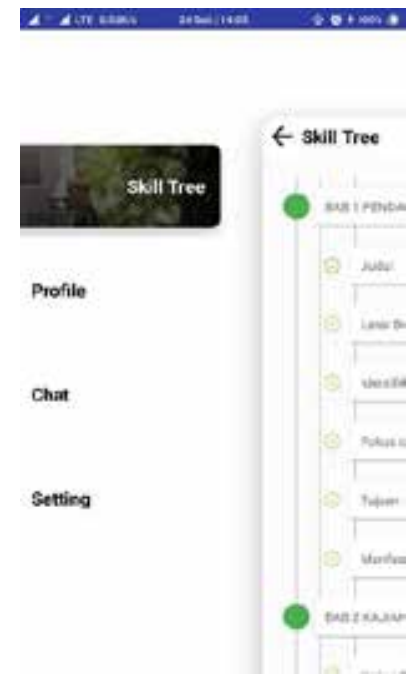

Figure 4. Software Main Menu Interface

The results of the hardware and software requirements analysis found that smartphones that are in the market and are still widely used are the 2014 smartphones with the Android Lollipop (Android firmware 5.0) operating system. Therefore the development of software prototypes developed on the Android operating system with Firmware 5.0 and above. The device used applies a minimum system such as the Motorola Moto G with specifications: (1) Chipset with Qualcomm MSM8226 Snapdragon $400(28 \mathrm{~nm})$, (2) CPU with Quad-core 1.2 GHz Cortex-A7, (3) GPU uses Adreno 305, (4) Internal Memory of 8/16 GB, 1 GB RAM, (5) WLAN with WiFi of $802.11 \mathrm{~b} / \mathrm{g} / \mathrm{n}$, hotspots, (6) 2G bands with GSM 850/900/1800/1900, (7) 3G bands with HSDPA 850/900/1700/1900/2100, (8) Speed of HSPA 21.1/5.76 Mbps, (9) GPRS, (10) EDGE, (11) Resolution of $720 \times 1280$ pixels, 16: 9 ratio ( $~ 326$ ppi density), and (11) Browser with HTML5.

The testing phase was then conducted after the initial product design (prototype) is ready. The tests were conducted in two ways, namely a limited trial and a test extensively. The tests were conducted on a real limited number of users to see the effectiveness of a product that includes the content, functionality, and connectivity. The tests were widely conducted also on real users with a wider scale with the intention that the software can be used elsewhere. Limited testing was performed before. Internal testing was first performed with quality assurance which includes content in general, functionality, and the connection.

The first software prototype testing was carried out using three smartphones with several levels of the operating system. The smartphones used are, (1) Meizu M2 fw 5.1, (2) Xiaomi Redmi Note 4 fw 7.0, (3) Xiaomi Mi $5 \mathrm{fw}$ 8.0. Some of these devices have firmware levels that are getting higher one each other, namely from firmware 5.1, 7.0, and 8.0. This is the need to be done to determine the compatibility of software on several devices that have different operating systems.

The results of the initial test on the application found that, (1) When the first download there was no installer data found, (2) The application icon in the Meizu M2 Device looks too rounded, (3) There is no loading indicator, (4) There is no permission to move the application to the memory card, (5) There is no indicator to access the main menu, (6) Information menu has not been provided, (7) There is no limit to the text entered except when entering an email that should be in the format of an e-mail address, (8) There is a problem when trying to create an account with special characters or symbols in the e-mail address and password, the application will display http 400 and then get stuck on the synchronization data, (9) After re-launching the profile that entered and loaded is the previous user's profile. When this happens, the user cannot chat because after selecting the lecturer, the Chat section will not be loaded (will re- 
select the lecturer menu), (10) There is no tutorial menu, (11) There is no setting menu, (12) The entry menu is not clear, (13) There is no copyright screen, (14) No exit confirmation screen message, (15) Many problems with the display when using landscape mode, (16) There is no sound notification.

The first test experienced many technical problems with device compatibility. But there are no problems that occur due to the application database. Therefore improvements are made by set some features that will still be used and eliminating features that are not needed to get optimum results.

Software that has these defects after being revised then assessed by material and media experts for the suitability of the software developed. Material experts assess the content of scientific writing that covers the beginning, core, and end of scientific writing. The results of the assessment by material experts for the suitability of scientific writing content were reviewed from the initial part of the scientific writing, namely $81.25 \%$ and had the category of very appropriate, at the core part of $79.76 \%$ and had the category of appropriate, and at the end of $50 \%$ and has the category of not appropriate. If all three are combined, the value obtained reaches $78.2 \%$ and gets a scale of appropriate.

The next step is an assessment by media experts on aspects of functionality, reliability, efficiency, usability, portability, and maintainability. The results of the assessment are obtained on the functionality aspect that is $95 \%$ and has the category of very appropriate, in the reliability aspect that is $100 \%$ and has the category of very appropriate, on the efficiency aspect that is $91.66 \%$ and has the category of very appropriate, on aspects usability is $80 \%$ and has a category of appropriate, on the portability aspect that is $100 \%$ and has the category of very appropriate, and on the maintainability aspect that is $95 \%$ and has the category of very appropriate.

From the data above, it can be concluded that the software developed is feasible and can be used but is still not optimal. Therefore experts provide several suggestions such as (1) Need to increase the number of characters in scientific works and the number per chapter; (2) Improvement of the research choice structure, and (3) It is necessary to add a data copy feature by the supervisor to correct written errors.

After the addition of the features suggested by the expert, a retest was carried out. The results obtained on the structure and technical testing showed that there were no defects in the products and the product can be operated smoothly. The structure and technical testing examine (1) the application can be run on a $2 \mathrm{~g}$ network, $3 \mathrm{~g}$, or $4 \mathrm{~g}$ (LTE), (2) installation process to the devices, (3) the correct icon form, (4) uninstalling the software, (5) re-installing process of the software, (6) launching and relaunching, (7) displaying orientation, (9) loading time, (8) no transition effect, (10) no cache after the relaunching, (10) not fast draining the battery, (11) available storage, (12) sensitive word (password), (13) idle, (14) google theme.

Testing on a general rule found several defects that are not too fatal and can still be repaired. Disability is a tutorial found on the first time you have yet to implement, the absence of key information, has provided input on the prohibition of the textbox, there has not been an indicator of whether the skill tree is already selected, the absence of the cancel button if you want to get out applications, and there are still some problems if run in landscape. However, the 
software is already viable use although there should be little improvement.

\section{CONCLUSION}

Teachers are required to be able to create and use media that meet the needs and demands the learning process that can improve the quality of education. The development of mobile technology stimulates the utilization of mobile technology as a medium of learning. Currently, it is used as an alternative media and may be used as a compulsory learning media in the future. Many applications now already implement artificial intelligence, especially in games. One of the methods applied in artificial intelligence in games is Skill Tree. Skill Tree is widely used in games but still limited to be applied in other fields especially education. This study shows that a skill tree applied as media education can mapping out the strengths and the weaknesses of students thus they can perform appropriate actions to support the students. This paper examines the development of Skill Tree as learning media. The results of the test structure and technical product testing reveals that there were no errors. The testing of a general rule showed an insignificant defect. Therefore the developed software can be generally considered eligible to be used and applied. This software is expected to help and facilitate the teacher to understand the weaknesses of the students and can improve the quality of education.

\section{REFERENCES}

[1] J. Kultgen, Ethics and Professionalism. Philadelphia: University Of Pennsylvania Press, 1988.
[2] J. Brown, The Definition of a Profession. New Jersey: Princeton University Press, 1992.

[3] T. Townsend and R. Bates, Handbook of Teacher Education: Globalization, Standards and Professionalism in Times of Change. Netherlands: Springer, 2007.

[4] C. E. Harris and M. S. Pritchard, Engineering Ethics: Concepts and Cases. Canada: Wadsworth, Cengage Learning, 2009.

[5] Ministry of National Education, The Law Number 14 Year 2005 regarding Teachers and Lecturers (Undangundang Nomor 14 Tahun 2005 tentang Guru dan Dosen). Ministry of National Education, 2005.

[6] Arsyad, Media Pembelajaran. Jakarta: Raja Grafindo Persada, 2006.

[7] R. E. Mayer, E-Learning and the Science of Instruction: Fourth Edition. Canada: John Wiley \& Sons,Inc., 2016.

[8] S. Kusumadewi, Artificial Intelligence (Teknik dan Aplikasinya). Yogyakarta: Graha Ilmu, 2003.

[9] Heinimäki, Technology Trees and Tools: Constructing Development Graphs for Digital Games. Tampere: Tampere University of Technology, 2015.

[10] Y. Ma, Liyau., Destercke, Sébastien., and Wang, "Online Active Learning of Decision Trees with Evidential Data," J. Pattern Recognit., vol. 52, pp. 33-45, 2016.

[11] P. Vizureanu, Advances in Expert Systems. Croatia: InTech, 2012.

[12] H. E. Kretser, "Mobile Decision-Tree Tool Technology as a Mean to Detect Wildlife Crimes and Build Enforcement Networks," J. Biol. Conserv., no. 189, pp. 33-38, 2015.

[13] A. Kassem, "A Value Tree for Identification of Evaluation Criteria for Solar Thermal Power Technologies in Developing 
Countries," J. Sustain. Energy Technol. Assessments, vol. 16, pp. 18-32, 2016.

[14] Suyitno, "Pengembangan Multimedia Interaktif Pengukuran Teknik untuk Meningkatkan Hasil Belajar Siswa SMK," J. Pendidik. Teknol. dan Kejuru., vol. 23, no. 1, pp. 101-109, May 2016.

[15] R. Arief and N. Umniati, "Pengembangan Virtual Class Untuk Pembelajaran Augmented Reality Berbasis Android. Jurnal Pendidikan Teknologi dan Kejuruan," $J$. Pendidik. Teknol. dan Kejuru., vol. 21, no. 2, pp. 114-122, 2012.

[16] A. Suryanto, D. A. Kusumawati, and I. M. H. Sanhoury, "Development of Augmented Reality Technology Based Learning Media of Lathe Machines," J. Pendidik. Teknol. dan Kejuru., vol. 24, no. 1, pp. 32-38, 2018.

[17] McCandless, “A Model Tree Approach to Forecasting Solar Irradiance Variability," J. Sol. Energy, vol. 120, pp. 514-524, 2015.

[18] L. Zhou, H. Fujita, and Y. W. Si, "Predicting The Listing Statuses Of Chinese-listed Companies Using Decision Trees Combined with an Improved Flter Feature Selection Method," J. Knowledge-Based Syst., vol. 128, 2017.
[19] R. S. Pressman, Software Engineering A Practitoner's Approach (Seventh Edition). New York: The McGraw-Hill Companies, Inc., 2010.

[20] W. Dick and L. Carey, The Systematic Design of Instruction, 8th ed. USA: : Pearson Education, Inc, 2015.

[21] Yucel, "Determination of Attitudes of Students Teachers towards the Utilization of Technology: Creating a Technology Tree," Procedia Soc. Behav. Sci., 2009.

[22] L. G. Morcillo, "Using Decision Trees for Comparing Different Consistency Models," Procedia Soc. Behav. Sci., vol. 160, pp. 332-341, 2014.

[23] A. Topîrceanua and G. Grosseck, "Decision tree learning used for the Classification of Students Archetypes in Online Course," Procedia Comput. Sci., vol. 112, pp. 51-60, 2017. 